CONGENITAL HEART DISEASE

\title{
Natural history of growth of secundum atrial septal defects and implications for transcatheter closure
}

\author{
C J McMahon, T F Feltes, J K Fraley, J T Bricker, R G Grifka, T A Tortoriello, R Blake, \\ L I Bezold
}

Heart 2002;87:256-259

See end of article for authors' affiliations

......................

Correspondence to: Dr Colin McMahon

LillieFrank Abercrombie

Division of Pediatric

Cardiology, Texas

Children's Hospital and

Baylor College of

Medicine, 6621 Fannin,

MC-2280 Houston, Texa

77030, USA

cmcmahon@bcm.tmc.edu

Accepted

29 October 2001

\begin{abstract}
Objective: To investigate the natural history of secundum atrial septal defects (ASDs) over several years using serial echocardiographic studies.

Methods: All patients with isolated secundum ASDs who had serial transthoracic echocardiograms at Texas Children's Hospital, Houston, Texas, from January 1991 to December 1998 were identified. Patients with fenestrated or multiple ASDs, other congenital heart defects, or less than a six month interval between echocardiograms were excluded. There were 104 patients eligible for inclusion in the study. Studies were reviewed by two echocardiographers (blinded) and the maximal diameter was recorded. Defects were defined as small $(>3 \mathrm{~mm}$ to $<6 \mathrm{~mm})$, moderate ( $\geqslant 6 \mathrm{~mm}$ to $<12 \mathrm{~mm}$ ), or large $(\geqslant 12 \mathrm{~mm})$. ASDs that grew $\geqslant 20 \mathrm{~mm}$ were defined as having outgrown transcatheter closure with the device available to the authors' institution.

Results: ASD diameter increased in 68 of 104 patients $(65 \%)$, including 31 patients $(30 \%)$ with a $>50 \%$ increase in diameter. Spontaneous closure occurred in four patients $(4 \%)$. Thirteen defects $(12 \%)$ increased to $\geqslant 20 \mathrm{~mm}$. One fifth of the patients studied had an insufficient atrial rim by transthoracic echocardiogram to hold an atrial septal occluder. The only factor associated with significant growth of ASDs was initial size of the defect. ASD growth was independent both of age at diagnosis and when indexed to body surface area.

Conclusions: Two thirds of secundum ASDs may enlarge with time and there is the potential for secundum ASDs to outgrow transcatheter closure with specific devices. Further development in devices and general availability of devices capable of closing larger ASDs should circumvent this problem.
\end{abstract}

A trial septal defects (ASDs) constitute the second most common congenital heart lesion in both adult and paediatric populations. ${ }^{1}$ The natural history remains poorly understood despite the significant attention focused on this lesion in recent years, particularly with regard to the optimum method of closure. Several investigators have studied the incidence of spontaneous closure of ASDs, concentrating primarily on small defects (generally defined as $<6 \mathrm{~mm}$ ), and reported a closure rate as high as $66 \% .^{1-5}$ Few studies, however, have assessed the natural history of larger defects. ${ }^{2}$

Over the past decade, the potential for transcatheter closure of ASDs has been realised with several devices currently available. The optimal device for closure is still under investigation and randomised trials comparing device with surgical closure are ongoing. The optimum timing for closure also remains contentious. The purpose of this study was to review retrospectively all patients presenting to the Texas Children's Hospital with isolated secundum ASD and to assess the change in maximal defect diameter as measured by sequential echocardiographic studies. From this data we sought to determine the risk of ASDs outgrowing the potential for device closure with Cardioseal or Starflex devices.

\section{METHODS}

\section{Patients}

A search of the Texas Children's Hospital echocardiographic database found 125 patients with a secundum ASD diagnosed between January 1991 and December 1998. There were 104 patients eligible for inclusion in the study. Inclusion criteria were the presence of an isolated ASD, the availability of serial echocardiographic data (at least two echocardiograms) with a minimum six month interval between echocardiograms, and satisfactory two dimensional echocardiogram image quality to allow accurate delineation of maximal ASD diameter. Exclusion criteria were defects with a diameter $<3 \mathrm{~mm}$, patent foramen ovale, the presence of other significant cardiac anomalies including pulmonary valve stenosis, and multiple or fenestrated ASDs.

The rate of change in size ( $\mathrm{mm}$ /year) of ASD, age at diagnosis, and interval of follow up were recorded. All echocardiograms were independently reviewed by two echocardiographers to avoid bias. The maximal size of the ASD from subcostal long and short axis two dimensional views was recorded. Measurements were taken only once the reviewer was satisfied that he had seen the ASD adequately in both planes to allow maximal diameter measurement. A minimum of eight cardiac cycles were examined as ASDs invariably undergo changes in configuration concordant with flow through the defect during different stages of the cardiac cycle. Colour Doppler was not used because of the risk of colour overspill giving erroneous measurements. In 20 patients we measured the septal rim changes to assess the incidence of insufficient rim diameter on the most recent echocardiogram. Interobserver and intraobserver variability were determined.

\section{Classification}

ASDs were classified by size. Small defects had a maximal diameter $>3 \mathrm{~mm}$ to $<6 \mathrm{~mm}$, moderate defects measured $\geqslant 6 \mathrm{~mm}$ to $<12 \mathrm{~mm}$ and large defects were $\geqslant 12 \mathrm{~mm}$.

\section{Statistical analysis}

Statistical analysis was performed using SSPS 7.5 for Windows (SPSS Inc, Chicago, Illinois). Data are expressed as mean (SD) (and range). Growth of different groups and variables such as age at diagnosis and indexed body surface area were compared by an analysis of variance. Regression analysis 
determined significant factors influencing growth. A probability value of $\mathrm{p}<0.05$ was defined as significant.

\section{RESULTS}

\section{Patient demographics}

An isolated ASD with no additional cardiac lesions was identified in 125 patients. One hundred and four patients were eligible after exclusion criteria. There were 70 female patients and 34 male patients (ratio 2.2:1). The mean age at diagnosis of the ASD was 4.5 years (range 0.1-71 years). The mean interval between echocardiograms was 3.1 years (range $0.7-8.1$ years $)$.

\section{Small ASD group}

At presentation 34 of 104 patients (33\%) had a defect $\geqslant 3 \mathrm{~mm}$ to $6 \mathrm{~mm}$ in diameter (fig 1). At follow up there were 27 small ASDs (26\%). Three defects closed spontaneously. Seventeen defects increased in size. Seven of these defects increased from the small to the moderate group and three defects increased from the small to the large group. In ASDs that increased from the small to the large group, the diameters increased from $3 \mathrm{~mm}$ to $22 \mathrm{~mm}, 3 \mathrm{~mm}$ to $17 \mathrm{~mm}$, and $3 \mathrm{~mm}$ to $15 \mathrm{~mm}$. The mean rate of increase in ASD size was 0.63 (1.6) $\mathrm{mm} /$ year for defects in this group (fig 2). The mean follow up was 3.2 years (range 0.9-7.1 years).

\section{Moderate ASD group}

At diagnosis 40 defects (38\%) were moderate sized and on follow up 32 defects $(31 \%)$ were moderate sized (fig 3). Three defects decreased to $<6 \mathrm{~mm}$ and eight defects increased to

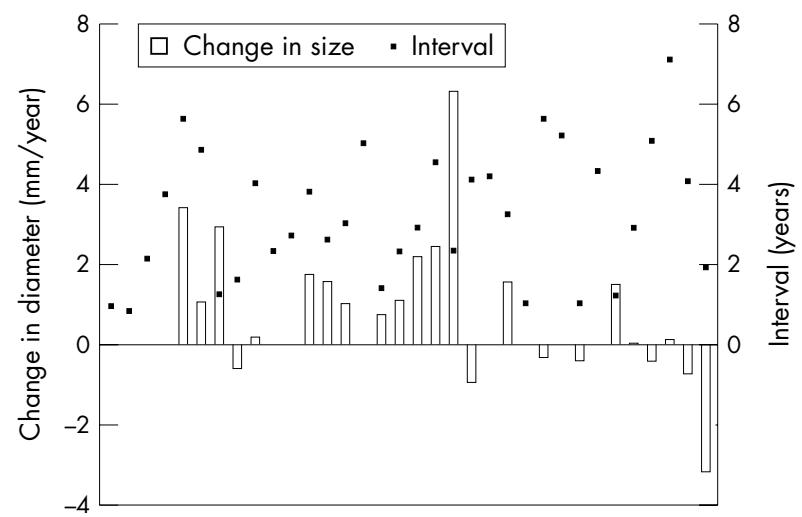

Figure 1 Rate of diameter change (mm/year) versus the number of years of follow up for the small defect group. The boxes on the $x$ axis represent the increase (above line) or decrease (below line) in diameter ( $\mathrm{mm} /$ year). The black dots represent the number of years of follow up for each respective defect.

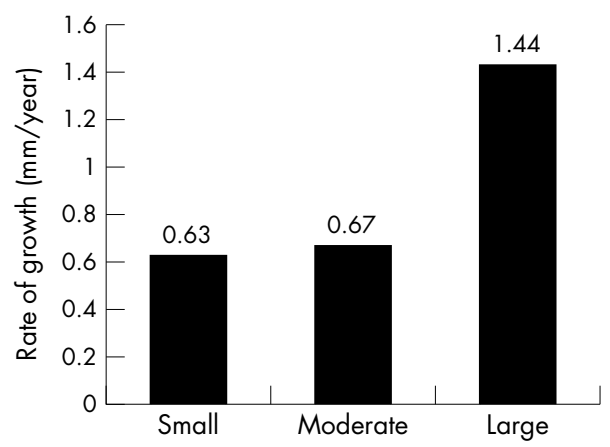

Figure 2 Rate of growth of defects (mm/year) in groups with small, moderate sized, and large atrial septal defects.

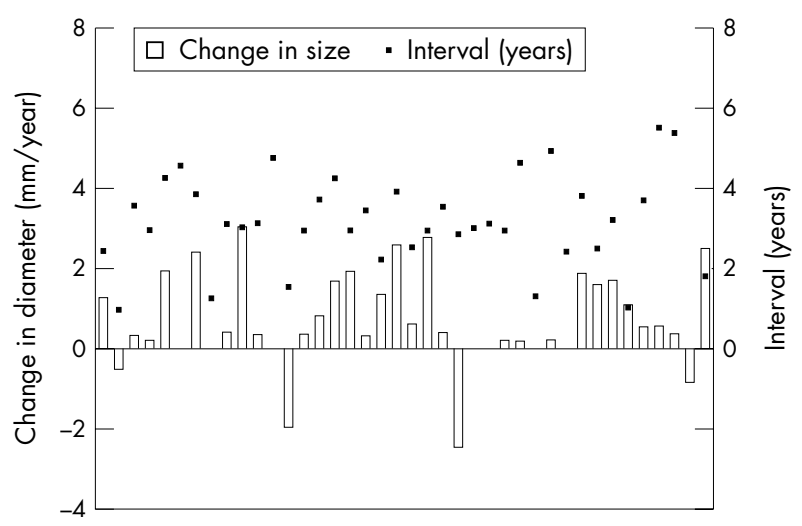

Figure 3 Rate of diameter change ( $\mathrm{mm} /$ year) versus the number of years of follow up (years) for the moderate sized group. The boxes on the $x$ axis represent the increase (above line) or decrease (below line) in diameter. The black dots represent the number of years of follow up for each respective defect.

$>12 \mathrm{~mm}$. The mean rate of ASD growth was 0.67 (1.6) mm/ year (fig 2). Mean follow up was 3.3 years (range 0.9-8.1 years).

\section{Large ASD group}

At diagnosis 30 defects were large (29\%) and on follow up 45 defects qualified as large (43\%) (fig 4). All patients with large defects remained in the same group. The mean increase in size was 1.44 ( 1.9 ) $\mathrm{mm} /$ year (fig 2). Mean follow up was 2.9 years (range $0.7-8.1$ years).

Overall the ASD diameter increased in 68 patients $(66 \%)$ at a rate of $0.8 \mathrm{~mm} /$ year (range $0.2-6.4 \mathrm{~mm} /$ year), including 31 $(30 \%)$ patients with $a \geqslant 50 \%$ increase in size. ASD size decreased in 15 patients (14\%) and was unchanged in 21 $(20 \%)$. The rate of growth was independent of age at diagnosis, ranging from $0.72 \mathrm{~mm} /$ year for the $2-4$ year age group to $1.29 \mathrm{~mm} /$ year for the 4-6 year age group, which was not significant $(p=0.9)$. Thirteen defects grew to $\geqslant 20 \mathrm{~mm}$ including one defect that increased from $3 \mathrm{~mm}$ to $22 \mathrm{~mm}$. The mean duration of follow up was 4.2 years (range 1.8-7.7 years) for defects that increased $\geqslant 20 \mathrm{~mm}$, indicating a tendency for continued ASD growth with time. Combining all defect groups, regression analysis showed a strong correlation between the initial size and the final size of defects with a $r^{2}=0.61$. There was a weak correlation between the initial size of the defect and the rate of growth of defects $\left(r^{2}=0.03\right)$;

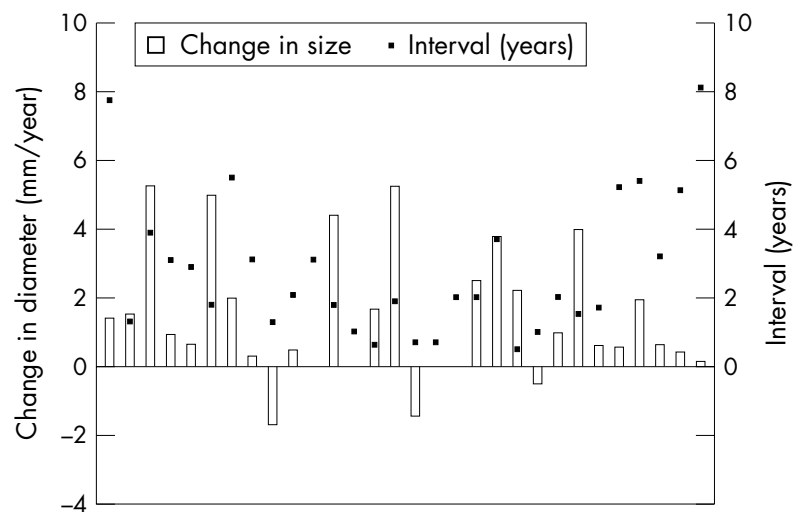

Figure 4 Rate of diameter change (mm/year) versus the number of years of follow up (years) for the large defect group. The boxes on the $x$ axis represent the increase (above line) or decrease (below line) in diameter. The black dots represent the number of years of follow up for each respective defect. 
however, this was significant with a $\mathrm{p}=0.05$. Interobserver variation was $8 \%$ and intraobserver variation was $5 \%$.

\section{Septal rim growth}

Twenty patients in whom there was ASD growth were reviewed and the superior and inferior septal rim were measured on sequential studies. The aortic rim could obviously not be assessed from transthoracic echocardiograms. The mean superior rim diameter increased from $7.1 \mathrm{~mm}$ (range $4.5-11.1 \mathrm{~mm}$ ) to $8.3 \mathrm{~mm}$ (range $5.4-13.1 \mathrm{~mm}$ ) and the mean inferior rim did not change: $6.1 \mathrm{~mm}$ (range $3.2-7.5 \mathrm{~mm}$ ) to $6.3 \mathrm{~mm}$ (range $4.1-7.6 \mathrm{~mm}$ ). Taking a minimal rim diameter of $\leqslant 5 \mathrm{~mm}$ to preclude transcatheter closure, 4 of 20 defects ( $20 \%$ ) would have been excluded based purely on rim size.

\section{DISCUSSION}

The natural history of secundum ASDs affects the need for and timing of closure either surgically or in the catheterisation laboratory. Our study showed that $65 \%$ of defects increase in diameter over a mean study period of 3.1 years, at a mean rate of $0.8 \mathrm{~mm} /$ year. In approximately $30 \%$ of patients, the ASD increased in size by $50 \%$ or more. There was also the potential for small defects, which were initially believed to be haemodynamically insignificant, to grow into major defects. If one considers a maximal diameter of $\geqslant 20 \mathrm{~mm}$ to be too large for transcatheter closure with the device available at our institution, then the ASD in 13 patients (12\%) outgrew the option for device closure during our mean study period of 3.1 years. Interestingly, the larger the defect at diagnosis, the greater the rate of growth. We speculate that growth of these ASDs is related to the increased blood flow (as indicated by the ratio of pulmonary to systemic blood flow) through larger defects and the intrinsically compliant nature of the atrial septum.

ASDs $<3 \mathrm{~mm}$ in diameter invariably close by 18 months of age and are generally regarded as patent foramen ovale. ${ }^{1}$ Spontaneous closure has been reported to occur in anywhere between $14-66 \%$ of ASDs. ${ }^{2-7}$ Factors such as smaller size of defect and earlier age at diagnosis led to early spontaneous closure. Cockerham and colleagues ${ }^{8}$ and Mody $y^{9}$ reported an increased likelihood of spontaneous closure in those diagnosed before two years of age. Radzik and associates ${ }^{1}$ concluded that the greatest predictor of spontaneous closure is initial ASD size at diagnosis. These authors have advocated following small ASDs with follow up studies at four years of age but the studies were limited in studying primarily small ASDs or patent foramen ovale, in which the diagnosis was made predominantly in the first year of life. The difference in natural history of our population group relates to broader ranges in the size of defect and patient age at the time of diagnosis.

Elective surgical closure of moderate sized to large ASDs is recommended between four and six years of age. ${ }^{10}{ }^{11}$ Since the realisation of transcatheter closure, first performed in 1976 by King and colleagues, ${ }^{12}$ it has become an attractive alternative to surgery, obviating the need for sternotomy and potential complications. Multiple devices are undergoing trials for this purpose. ${ }^{13-18}$ Significant debate remains as to the optimal timing and mode of closure. Prospective studies of outcome and complications of surgical compared with transcatheter closure are eagerly awaited. Limited data to date have shown equal closure and complication rates with a significantly shorter hospitalisation duration following transcatheter closure. ${ }^{15} 19$

There does not appear to be any significant benefit in ASD closure before 3-5 years of age in small to moderate sized asymptomatic defects. ${ }^{19}$ However, with age, the risk of growth of ASDs remains a genuine concern, particularly to families electing to avoid surgery. These data support vigilant monitoring of all defects in the first few years after diagnosis and, in keeping with current recommendations, surveillance echocardiography between 18-24 months after diagnosis. If a defect, particularly in the larger group, grows appreciably then early referral for transcatheter closure when the child has a safe weight and size to tolerate device implant seems logical.

\section{Study limitations}

The major limitation of this study is that it was retrospective. Secondly, there are inherent limitations in measuring secundum ASDs, as some may have an elliptical shape and the maximum diameter not only may be difficult to interpret but also may change during the cardiac cycle; hence, at least eight cardiac cycles were examined. ${ }^{20}$ We took measurements as valid only once we could assess the atrial septum adequately in both axes to measure a truly representative maximal diameter. Ideally, however, a three dimensional view of the septum (for example, three dimensional echocardiography) may have shown a larger maximal diameter. Bias was reduced by observers being blinded to the time of study. The true potential for ASDs to grow even further may not have been fully realised, as many patients underwent early surgical or transcatheter device closure. Larger ASDs most likely were referred early for closure and the true potential for growth in this group may have been underestimated. The study population comprised a large female component, which also may have represented a bias in sex referral pattern for surgical and transcatheter closure. Growth of ASDs may be due to stretching of the defect in the direction opposite to the short axis of the ellipsoid shape of the defect or may be secondary to continuous shunting maintaining defect patency. ${ }^{21}$ We did not, however, investigate whether defect shape, ratio of pulmonary to systemic blood flow, or right heart volume overload predisposed ASDs to grow.

\section{Implications}

This study has important implications because $12 \%$ of our study population outgrew the option of closure with a device over the study period (using Cardioseal or Starflex devices), based purely on ASD growth. This is characterised by any defect that has grown to $20 \mathrm{~mm}$ in diameter (for the device specific to our institution). If one assumes a birth rate of 14.5 per 1000 in the USA ( 1997 census report) with ASDs accounting for $12-14 \%$ of all congenital heart defects and with a congenital heart disease incidence of 8 per 1000, one can surmise that approximately 200 patients per year outgrow the option of placement of the above devices. ${ }^{22}$ Additionally, transthoracic measurement generally underestimates the stretched ASD diameter and the number of patients who are ineligible for device closure according to our criteria may be underestimated. ${ }^{23}$ One can infer from these data that delays in device approval has significant implications for patients awaiting device implantation if they present to institutions with this restricted device availability, particularly for children with larger atrial secundum defects.

The Amplatzer septal occluder (AGA Medical Corp, Golden Valley, Minnesota) is available in selected institutions in the USA and throughout Europe and can close ASDs with a stretched diameter between $36-38 \mathrm{~mm}^{24-26}$ Some patients in our study with ASDs too large for Cardioseal occlusion may have been candidates for closure with the Amplatzer septal occluder. Selection criteria for closure using this device requires a rim of at least $5-7 \mathrm{~mm} .{ }^{24}$ Safe implantation requires a left atrial diameter equal to the stretched diameter and twice the minimal rim diameter. In the majority of cases the waist of the device equals the stretched diameter, although in larger defects a waist $2 \mathrm{~mm}$ larger is used to ensure stability of the device. A recent report of the use of three dimensional echocardiography to compare the geometric profiles of Amplatzer and Cardioseal devices showed that the Amplatzer device assumed a ball-like shape in the atria. Although it does 
allow closure of large ASDs potential complications include atrioventricular node injury and obstruction to the superior vena cava or mitral apparatus. ${ }^{27}$

\section{Conclusions}

In conclusion, up to two thirds of isolated secundum ASDs grow over intermediate term follow up. A subset of ASDs may outgrow the potential for transcatheter device closure with specific devices, including patients originally thought to have small ASDs. Further developments in pre-existing devices and general availability of other devices capable of closing larger ASDs should help circumvent this problem.

\section{ACKNOWLEDGEMENT}

We would like to express our gratitude to Melissa Mayo of the Texas Heart Institute for generating the graphs.

\section{Authors' affiliations}

C J McMahon, J T Bricker, R G Grifka, T A Tortoriello, R Blake, L I

Bezold, The LillieFrank Abercrombie Division of Pediatric Cardiology, Texas Children's Hospital and Baylor College of Medicine, Houston, 6621 Fannin, Texas 77030, USA

T F Feltes, Department of Pediatric Cardiology 700 Children's Drive, Columbus, Ohio 43205, USA

J K Fraley, Department of Biostatistics, Children's Nutrition Research Center, Houston, Texas, USA

Dr McMahon is supported by an Abercrombie Grant from the Division of Pediatric Cardiology, Texas Children's Hospital, Houston, Texas, USA.

Presented at the 73rd Scientific Sessions of the American Heart Association, New Orleans, Louisiana, USA, 12-15 November 2000.

\section{REFERENCES}

1 Radzik D, Davignon A, von Doesburg N, et al. Predictive factors for spontaneous closure of atrial septal defects diagnosed in the first 3 months of life. J Am Coll Cardiol 1993;22:851-3.

2 Helgason $\mathbf{H}$, Jonsdottir $\mathbf{G}$. Spontaneous closure of atrial septal defects. Pediatr Cardiol 1999;20:195-9.

3 Brassard M, Fouron JC, van Doesburg NH, et al. Outcome of children with atrial septal defect considered too small for surgical closure. Am J Cardiol 1999:83:1552-5

4 Hartmann AF, Elliott LP. Spontaneous physiologic closure of an atrial septal defect after infancy. Am J Cardiol 1967;19:290-2.

5 Fukasawa M, Fukushige J, Ueda K. Atrial septal defect in neonates with reference to spontaneous closure. Am Heart J 1988;1 16:123-7.

6 Giardina AC, Raptoulis AS, Engle MA, et al. Spontaneous closure of atrial septal defect with cardiac failure in infancy. Chest 1979;75:395-7.
7 Mahoney LT, Truesdell SC, Krzmarzick TR, et al. Atrial septal defects that present in infancy. Am J Dis Child 1986;140:1115-8.

8 Cockerham JT, Martin TC, Gutierrez FR, et al. Spontaneous closure of secundum atrial septal defect in infants and young children. Am J Cardiol 1983:52:1267-71.

9 Mody MR. Serial hemodynamic observations in secundum atrial septal defect with special reference to spontaneous closure. Am J Cardiol 1973;32:978-81

10 Murphy JG, Gersh BJ, McGoon MD, et al. Long term outcome after surgical repair of isolated atrial septal defect. Follow-up at 27 to 32 years. N Engl J Med 1990;323:1645-50.

11 Black MD, Freedom RM. Minimally invasive repair of atrial septal defects. Ann Thorac Surg 1998;65:765-7.

12 King TD, Thompson SL, Steiner C, et al. Secundum atrial septal defects: nonoperative closure during cardiac catheterization. JAMA 1976:235:2506-9.

13 Das GS, Voss G, Jarvis G, et al. Experimental atrial septal defect closure with a new, transcatheter, self-centering device. Circulation 1993;88: 1754-64.

14 Babic UU, Grujicic S, Popovic Z, et al. Double-umbrella device for transvenous closure of patent ductus arteriosus and atrial septal defect: First experience. J Interv Cardiol 1991;4:283-94.

15 Berger F, Vogel M, Alexi-Meskishvili V, et al. Comparison of results and complications of surgical and Amplatzer device closure of atrial septal defects. J Thorac Cardiovasc Surg 1999;1 18:674-80.

16 Hausdorf G, Schneider M, Franzbach B, et al. Transcatheter closure of secundum atrial septal defects with the atrial septal defect occlusion system (ASDOS): initial experience in children. Heart 1996;75:83-8.

17 Sideris EB, Rao PS. Transcatheter closure of atrial septal defects: role of buttoned devices. J Invasive Cardiol 1996;8:289-96

18 Latson LA. Per-catheter ASD closure. Pediatr Cardiol 1998;19:86-93.

19 Konstantinides S, Geibel A, Olschewski M, et al. A comparison of surgical and medical therapy for atrial septal defect in adults. N Engl J Med 1995;333:469-73

20 Cayler GG. Spontaneous functional closure of symptomatic atrial septal defects. N Engl J Med 1967;276:65-73.

21 Ventura SJ, Martin JA, Curtin SC, et al. National vital statistics report. Bethesda: Centers for Disease Control and Prevention, National Center for Health Statistics 2000;48: 1-100.

22 Franke A, Kuhl HP, Rulands D, et al. Quantitative analysis of the morphology of secundum-type atrial septal defects and their dynamic change using transesophageal three-dimensional echocardiography. Circulation 1997;96(suppl II):323-7.

23 Rao PS, Langbough R. Relationship of echocardiographic, shunt flow, and angiographic size to stretched diameter of the atrial septal defect. Am Heart J 1991; 122:505-8.

24 Walsh KP, Maadi IM. The Amplatzer septal occluder. Cardiol Young 2000;10:493-501.

25 Vogel M, Berger F, Dahnert I, et al. Treatment of atrial septal defects in symptomatic children aged less than 2 years of age using the Amplatzer septal occluder. Cardiol Young 2000:10:534-7.

26 Dhillon R, Thanopoulos B, Tsaousis G, et al. Transcatheter closure of atrial septal defects in adults with the Amplatzer septal occluder. Heart 1999;82:559-62

27 Acar $\mathbf{P}$, Saliba Z, Bonhoeffer $\mathrm{P}$, et al. Assessment of the geometric profile of the Amplatzer and Cardioseal septal occluders by three dimensional echocardiography. Heart 2001;85:451-3.

Link to Medline from the homepage and get straight into the National Library of Medicine's premier bibliographic database. Medline allows you to search across 9 million records of bibliographic citations and author abstracts from approximately 3,900 current biomedical journals. 